\title{
Beliefs, Anxiety, and Avoiding Failure in Mathematics
}

\author{
Steve Chinn \\ Faculty of Education, Health and Sciences, University of Derby, Derby DE22 1GB, UK \\ Correspondence should be addressed to Steve Chinn, steve.chinn@btinternet.com
}

Received 1 June 2012; Revised 26 August 2012; Accepted 29 August 2012

Academic Editor: Ann Dowker

Copyright (C) 2012 Steve Chinn. This is an open access article distributed under the Creative Commons Attribution License, which permits unrestricted use, distribution, and reproduction in any medium, provided the original work is properly cited.

\begin{abstract}
Mathematics anxiety has been the subject of several books and numerous research papers, suggesting that it is a significant issue for many people. Children and adults develop strategies to cope with this anxiety, one of which is avoidance. This paper presents data taken from over 2500 mathematics test papers in order to compare the levels of accuracy and the frequency of the use of the "no attempt" strategy, that is, avoidance, for arithmetic problems given to children aged from 10 years to adults aged up to 49 years from across the UK.
\end{abstract}

\section{Introduction}

The difficulties in learning mathematics are a fascinating and complex area for study. The interactions between factors that can be attributed to the cognitive domain and those that can be attributed to the affective domain are many and varied. For example, anxiety has a negative influence on working memory [1]. Skemp ([2], page 127) suggested that the reflective activity of intelligence is most easily inhibited by anxiety. Lundberg and Sterner [3] claim that "over and above common cognitive demands and neurological representations and functions, performance in reading and arithmetic is influenced by a number of motivational and emotional factors such as need for achievement, task orientation, helplessness, depression, anxiety, self-esteem, selfconcept. ..." Hattie [4] selects a pithy quote from O'Connor and Paunonen [5], "Whereas cognitive ability reflects what an individual can do, personality traits reflect what an individual will do."

The implications on learning of anxiety, motivation, selfworth, self-efficacy and attributional style are significant (e.g., [6-8]) particularly in mathematics where a curriculum may make inappropriate assumptions about how some children learn. Those assumptions may be rooted in beliefs about mathematics and how it can be taught and learnt.

There are a number of beliefs about mathematics that are long established and embedded in its culture. This does not necessarily make them helpful in creating a positive student attitude to mathematics, especially for those who have difficulties with learning mathematics or, indeed, mathematics learning difficulties. For example, Mtetwa and Garofalo [9] discuss five beliefs, which include "mathematics problems have only one correct answer" and "computation problems must be solved by using a step-by-step algorithm." The first belief leads children to perceive of mathematics as highly judgmental, that answers are right or they are wrong. The second belief leads children and their teachers to perceive of mathematics as a series of procedures which have to be memorised and not necessarily understood. Ernest [10] reviews the literature on beliefs in his book, "The Psychology of Learning Mathematics." Three examples from his review are "some people have a mathematics mind and some do not," "mathematicians do problems quickly in their head," and "mathematics requires a good memory". The first belief permits people to rationalise their inabilities in mathematics and to protect their feelings of self-worth. The second belief sets up children who process some information more slowly, for example dyslexic children, for failure. The last belief is pervasive, for example, Porkess et al. [11] claims that "As with any language, the fundamentals of mathematics (e.g., multiplication tables and number bonds) are most easily learnt when you are young." Unfortunately the reliance on memorising facts and procedures does not stop there. 
It could be hypothesised that these beliefs have been, and still are, influential in the way mathematics' curricula are designed and in the way mathematics is taught. For example, the beliefs that surround the task of learning times table facts, where the primary belief is that, providing the child practises enough, then the learning is guaranteed and achieved early in the child's life. Informal surveys of teachers across the UK by the author lead to an estimate of somewhere around $50 \%$ of ten-year-old students failing to achieve this goal. Evidence on levels of achievement in retrieving basic facts acquired from a large sample of pupils from across the UK can be found in Chinn [12].

The implications of the experience of failure in learning are succinctly described in the back-cover summary of Covington's [13] book on motivation:

"Achievement behaviour in schools can best be understood in terms of attempts by students to maintain a positive self-image. For many students, trying hard is frightening because a combination of effort and failure implies low ability, which is often equated with worthlessness. Thus many students described as unmotivated are in actuality highly motivated-not to learn, but to avoid failure."

The experience of failure is a consequence of the inherently judgmental nature of arithmetic. For example, the answer for $8 \times 7$ is 56 . Giving an answer of 54 is rarely judged empathetically as, "That was close. Well done." The " 54 " answer generates the response, "Wrong." Arithmetic is, unavoidably, the dominant experience of mathematics for young pupils.

Failure and the judgmental nature of mathematics contribute to anxiety. In Chinn's [14] survey of mathematics anxiety in over 2500 secondary students (ages 11 to 15 years) in England, the item "waiting to hear your score on a maths test" was ranked high for anxiety, that is, from second to 6th out of 20 items for all ages and both genders of mainstream students. "Having to take a written maths test" was ranked from second to 4th and "taking an end of term maths exam" was ranked first out of 20 items for all pupils.

The mathematics task which ranked highest was, "doing long division questions without a calculator", ranking from second to 5th. "Long multiplication without a calculator" was ranked less highly, between 9th and 13th for ten of the fifteen subgroups of students.

The ranking of the item, "having to work out the answers to maths questions quickly," which reflects the mathematics belief that computations have to be done quickly, was also ranked high, for both the dyslexic (442 males) and the mainstream school students (2084 male and female) in the sample. The anxiety generated by having to attempt a problem that is a threat to the pupil's confidence is often exacerbated by the need to work out an answer quickly, that is, within an arbitrary time limit.

Studies from many countries over many years have shown that performance in mathematics is related negatively to mathematics anxiety ([15, page 249$]$, [16, page 334$]$, and $[17,18])$.

Failure can motivate or undermine ([6, page 5]) depending on whether students' reactions are mastery-oriented or helpless. Dweck uses the term "helpless" to include all the reactions that some students show when they meet failure, including plunging expectations, negative emotions, and deteriorating performance. It seems that the consequence of failure in mathematics is to undermine.

One reaction, or strategy, to deal with failure that Chinn [19] observed in a classroom study on errors in arithmetic is to avoid the challenge and use the "no attempt" [20] error. The study was set up to compare both the performance and the errors for pupils in mainstream schools to those for dyslexic pupils in specialist schools (ages 11 to 13 years). There appeared to be no difference in the frequency of occurrence of any of Engelhardt's other categories of errors, but the one outstanding exception was the "no attempt" error. For example, for $37.6-4,14.0 \%$ of the dyslexic pupils did not attempt the item compared to $2.2 \%$ of the mainstream pupils. This compared to the addition item, $12.3+5$ (where finger counting forwards is a strategy that is accessible to almost all children) where the no attempt percentages were $2.5 \%$ and $0 \%$, respectively. For division the contrast was greater, for the item, $6040 \div 10,39.7 \%$ of the dyslexic cohort did not attempt the problem in comparison to $5.8 \%$ of the mainstream cohort. The study suggested that children with specific learning difficulties, even if of above average intelligence, or perhaps because they are of above average intelligence, will use avoidance rather than risk failure. Data from a 15-minute mathematics test [12], the source of the data for this paper, is given for the bottom and top quartiles of performers to support this conjecture.

Hadfield and McNeil [21] proposed a model of mathematics anxiety, centred on three factors. Environmental factors include classroom issues and the perception of mathematics as a rigid set of rules. Intellectual variables include a mismatch of learning styles and self-doubt. Personality factors include a reluctance to ask questions in class and low self-esteem. Any or all of these three factors could influence a learner and generate a "no attempt" or avoidance attitude.

It is unlikely that this reaction is confined solely to the special needs population, nor just to avoidance of individual questions. Ashcraft and Krause [17] note that "Mathematics anxiety leads to a global avoidance pattern-whenever possible, students avoid taking math classes and avoid situations in which math will be necessary..."

The problem of avoidance begins when some children are quite young. An informal survey by the author, taken over the past ten years, of hundreds of teachers from across the UK and abroad indicates that enough children at age 7 years are withdrawing from and giving up on maths for classroom teachers to notice.

The English Government ([22], page 17) has noted that a "minority of pupils" who were making less than expected progress in mathematics shared certain characteristics, including the following.

They would work if the task was straightforward, but would get distracted and might behave badly if they decided they could not do the work.

They did not want to be told they had got something wrong-they were likely to give the impression that they did not care and give up.

They were concerned about how their peers viewed them-for some it was a risk to be seen to try and fail. 
TABLE 1

\begin{tabular}{lccc}
\hline Age & Sample & $\begin{array}{c}34=4+- \\
\text { Percentage of correct answers }\end{array}$ & Percentage of "no attempts" \\
\hline $8 \mathrm{y}$ & 225 & 62.2 & 10.2 \\
$10 \mathrm{y}$ & 220 & 77.7 & 5.5 \\
$12 \mathrm{y}$ & 173 & 84.4 & 2.9 \\
$40-49 \mathrm{y}$ & 129 & 92.2 & 1.6 \\
\hline
\end{tabular}

TABLE 2

\begin{tabular}{lccc}
\hline & & $9=--4$ & \\
Age & Sample & Percentage of correct answers & Percentage of "no attempts" \\
\hline $8 \mathrm{y}$ & 225 & 36.9 & 22.2 \\
$10 \mathrm{y}$ & 220 & 72.3 & 9.5 \\
$12 \mathrm{y}$ & 173 & 71.1 & 9.2 \\
$14 \mathrm{y}$ & 225 & 81.3 & 5.3 \\
$40-49 \mathrm{y}$ & 129 & 82.9 & 4.7 \\
\hline
\end{tabular}

These observations were personalised by a quote (p18) from a Year 9 (13 years old) girl:

"I don't get stuck in other subjects-only maths. When I'm doing English, I can always get on with my work. If I'm not sure about a spelling, I can just have a go and still get my work done. But I can't do that in maths. If I'm stuck I can't do anything but wait for help. Then I don't get anything done."

\section{The Sample}

1783 school children from age 7 years to 15 years old. 792 people from age 16 years to 59 years old.

The sample was collected from across the UK from over 50 sources, including state schools, independent schools, colleges, a prison, postal workers, and college students. The majority of the data was collected over a period of twelve months, mid 2010 to mid 2011. Only one of the schools that participated was a special school (for dyslexic pupils).

\section{The Test/Survey}

The data was collected as a consequence of setting up a 15minute norm-referenced test/survey of mathematics [12]. The "test" was renamed for adults as a "survey" in an attempt to lower anxiety levels and thus to encourage more of them to take part. The tactic was marginally successful.

The test consists of 44 items, ranging from $2+5=-$, to "Write forty thousand and seventy as a number," to $20 \%$ of 140 , to $2 y+5=31$. It is, however, primarily a test of arithmetic.

\section{The Results}

A number of hypotheses follow, stimulated by the analysis of the data collected for the standardising procedure combined with reflections on the author's previous research and thirty years of teaching experience with students with specific learning difficulties. This analysis of the data is in terms of the percentage of correct answers and the percentage of "no attempts." A "no attempt" may have been caused by the subject having not yet reached the relevant stage in the curriculum. The National Numeracy Strategy for England was referred to in order to ascertain at what age a topic is included in the curriculum in order to minimise this problem.

4.1. Hypothesis 1. Addition is the default operation. The other operations create less success, more insecurity and more "no attempt" errors (see Table 1).

This item is testing knowledge of place value at a basic level of two-digit numbers. It is less about testing addition skills, although a + sign is present. The percentage of correct answers grows steadily between 8 years and 12 years old and is at a slightly higher level for the 40 to 49 years old group. The percentage of "no attempts" is marginal at 12 years and older.

The problem in Table 2 is a basic fact presented as a subtraction with a missing number and in the reverse order to basic fact format, that is, $--4=9$. For those pupils who are heavily dependent on consistency, even this simple change in order may be a challenge. The percentage of pupils aged 10 and 12 years who did not get a correct answer was high at $27.7 \%$ and $28.9 \%$, respectively. Almost 1 in 10 pupils of these ages did not attempt the question. This dropped to almost 1 in 20 at 14 years old. These figures suggest that subtraction is perceived as being more difficult than addition.

An item, which requires the subject to cross the tens (see Table 3), provides further evidence to suggest that addition is believed to be easier than subtraction. The percentages of 
TABLE 3

\begin{tabular}{lccc}
\hline $\begin{array}{l}36 \\
+54 \\
\text { Age }\end{array}$ & & & \\
\hline $8 \mathrm{y}$ & Sample & Percentage of correct answers & Percentage of "no attempts" \\
$10 \mathrm{y}$ & 225 & 71.6 & 7.6 \\
$13 \mathrm{y}$ & 220 & 92.7 & 1.0 \\
$14 \mathrm{y}$ & 191 & 92.7 & 1.6 \\
$40-49 \mathrm{y}$ & 225 & 92.4 & 0.9 \\
\hline
\end{tabular}

TABLe 4

\begin{tabular}{lccc}
\hline $\begin{array}{l}103 \\
-96\end{array}$ & & & \\
Age & Sample & Percentage of correct answers & Percentage of "no attempts" \\
\hline $8 \mathrm{y}$ & 225 & 29.3 & 34.7 \\
$10 \mathrm{y}$ & 220 & 63.6 & 7.7 \\
$13 \mathrm{y}$ & 191 & 69.6 & 8.9 \\
$14 \mathrm{y}$ & 225 & 79.6 & 5.8 \\
$40-49 \mathrm{y}$ & 129 & 93.0 & 1.6 \\
\hline
\end{tabular}

correct answers are higher and the percentages of "no attempts" are lower than for the subtraction item, 103 - 96, particularly for the school pupils (see Table 4).

The National Numeracy Strategy includes subtraction problems of the type HTU-TU in Year 4 (8 years old).

The results shown in Table 4 indicate that around onethird of pupils aged from 10 to 13 years old cannot obtain a correct answer to this question. A number of the answers given, for example 193, were manifestly incorrect.

The problem shown in Table 5 is about the commutative property. If that is recognised, then the answer is achieved quickly and accurately. If it is not recognised then the method is to add 534 and 185, giving an interim answer of 719, followed by subtracting 185 . The item uses three-digit numbers and thus may be perceived as more challenging. Even though the item uses the low anxiety inducing + sign, the percentage of "no attempts" is the highest for the examples listed so far which incorporate the + symbol. It is noteworthy that the percentage of "no-attempts" is now higher than for other addition problems in the test for the 40 to 49 year olds, who may not have the frequent exposure to the commutative property of numbers that schoolchildren do.

The hypothesis may require a caveat, in that once the addition problem becomes more challenging or is perceived as more challenging, the security of "doing" addition is weakened. This caveat may be required for other hypotheses.

It can be tempting for teachers who feel that a lesson is going well to push the concept a step beyond the comfort zone of some learners.

4.2. Hypothesis 2. Multiplication is not widely understood and is judged as difficult, so more learners avoid the risk of being wrong.
Caveat: simply learning the times table facts by rote may not help in building an early understanding of the concepts of multiplication (or division).

The multiplication item in Table 6 was designed to not require the retrieval of any of the basic multiplication facts that are often perceived as difficult (to retrieve). It requires only a retrieval of $2 \mathrm{x}$ and $3 \mathrm{x}$ facts. Thus, the item is testing the ability to use a procedure. The procedures that can be used all require the ability to organise, spatially and cognitively, a relatively large amount of information on the page.

The percentage of correct answers increases from age 13 years to age 16-19 years old, but remains well under $50 \%$. The percentage of "no attempts" is around 34\% for ages 16 to 39 years and then drops to around $15 \%$ for ages 40 to 59 years. This could suggest that whatever the methods taught, the "traditional long multiplication" or the more recently favoured grid method, they are not creating enduring security and efficacy for people after-school. Even methods that resulted in a correct answer sometimes indicated a rigid adherence to procedure, for example, a $15 \mathrm{y} 9 \mathrm{~m}$ student wrote:

\begin{tabular}{c}
541 \\
$\times 203$ \\
\hline 1623 \\
0000 \\
108200 \\
\hline 109823
\end{tabular}

However, among 15-year-old students this method, which uses partial products selected via the place values of the digits in the multiplying number, was the preferred 
TABle 5

\begin{tabular}{lccc}
\hline & & $534+185=185+_{--}$ & \\
Age & Sample & Percentage of correct answers & Percentage of "no attempts" \\
\hline $10 \mathrm{y}$ & 220 & 52.7 & 12.3 \\
$13 \mathrm{y}$ & 191 & 70.7 & 12.7 \\
$15 \mathrm{y}$ & 220 & 82.3 & 10.0 \\
$40-49 \mathrm{y}$ & 129 & 77.5 & 15.5 \\
\hline
\end{tabular}

TABle 6

\begin{tabular}{lccc}
\hline 541 & & & \\
$\times 203$ \\
Age & Sample & Percentage of correct answers & Percentage of "no attempts" \\
\hline 13 y & 191 & 15.2 & 40.8 \\
$14 y$ & 225 & 27.1 & 22.2 \\
$15 y$ & 220 & 38.2 & 16.8 \\
$16-19 y$ & 307 & 33.2 & 32.6 \\
$20-29 y$ & 160 & 33.1 & 34.4 \\
$30-39 y$ & 108 & 32.4 & 33.3 \\
$40-49 y$ & 129 & 57.4 & 16.3 \\
$50-59 y$ & 88 & 52.3 & 13.6 \\
\hline
\end{tabular}

TABle 7

\begin{tabular}{lccc}
\hline & & $2) \overline{38}$ & \\
Age & Sample & Percentage of correct answers & Percentage of "no attempts" \\
\hline $10 \mathrm{y}$ & 220 & 59.1 & 27.5 \\
$13 \mathrm{y}$ & 191 & 60.7 & 13.2 \\
$15 \mathrm{y}$ & 220 & 75.0 & 20.8 \\
$16-19 \mathrm{y}$ & 307 & 67.8 & 8.5 \\
$40-49 \mathrm{y}$ & 129 & 86.0 & 8.5 \\
\hline
\end{tabular}

method and usually led to a correct answer. Place value and partial product-based errors included

$$
\begin{array}{rr}
541 & 541 \\
\times 203 & \times 203 \\
\hline 1043 & 1003 \\
541 & 541 \\
\times 203 & \times 203 \\
\hline 10820 & 1623 \\
0000 & 000 \\
\frac{1623}{11443} & \frac{1082}{2705}
\end{array}
$$

The insecurity, fear of failure, and anxiety created by multiplications that are perceived of as complex and demanding are likely to contribute significantly to the high percentage of "no attempts". A 59-year-old, successful, business man who scored 39/44 simply wrote "too hard" next to this item and moved on.

The percentages for correct answers suggest that whatever is happening to teach multiplication in many mathematics classrooms is not successful for a large proportion of learners.
4.3. Hypothesis 3. Division is even less understood than multiplication (and is rarely linked to multiplication in learners' minds) and is judged by learners as being even more difficult, so that more children and adults will avoid the risk of being wrong (see Table 7).

This item is at a low level of complexity. It could be viewed as "halving 38."

The percentage of "no attempts" is high for the 10 years and 13 years cohorts, representing between a third and a quarter who did not take the risk of attempting this item. Even at 40 years, the "no attempt" percentage showed that approximately 1 in 12 did not attempt a division by 2 (see Table 8).

Even though this item is still a division by a single digit number, it did create high percentages of "no attempts" and low percentages of correct answers, data that, when compared with the $541 \times 203$ item shows that the percentages of "no attempts" for this division item were higher than for the multiplication item (see Tables 9 and 10).

For the latter two items the percentages of "no attempts" are high. Both items could be considered to be, fundamentally, about place value. The "rules" about moving the decimal place when multiplying and dividing by powers of 
TABLE 8

\begin{tabular}{|c|c|c|c|}
\hline \multicolumn{4}{|c|}{ 9)927 } \\
\hline Age & Sample & Percentage of correct answers & Percentage of "no attempts" \\
\hline $13 y$ & 191 & 41.9 & 36.1 \\
\hline $14 \mathrm{y}$ & 225 & 47.6 & 29.8 \\
\hline $15 y$ & 220 & 45.5 & 32.3 \\
\hline $16-19 y$ & 307 & 38.1 & 46.0 \\
\hline $20-29 y$ & 160 & 31.2 & 45.6 \\
\hline $40-49 y$ & 129 & 55.8 & 26.4 \\
\hline \multicolumn{4}{|c|}{ TABLE 9} \\
\hline \multicolumn{4}{|c|}{$1 0 \longdiv { 6 0 3 0 }$} \\
\hline Age & Sample & Percentage of correct answers & Percentage of "no attempts" \\
\hline $10 y$ & 220 & 44.5 & 31.4 \\
\hline $11 \mathrm{y}$ & 200 & 44.5 & 23.0 \\
\hline $13 y$ & 191 & 48.7 & 27.2 \\
\hline $15 y$ & 220 & 62.3 & 14.5 \\
\hline $16-19 y$ & 307 & 56.5 & 22.8 \\
\hline $40-49 y$ & 129 & 77.5 & 7.8 \\
\hline
\end{tabular}

TABle 10

\begin{tabular}{|c|c|c|c|}
\hline \multicolumn{4}{|c|}{$23 \div 1000$} \\
\hline Age & Sample & Percentage of correct answers & Percentage of "no attempts" \\
\hline $13 y$ & 191 & 31.4 & 38.7 \\
\hline $14 \mathrm{y}$ & 225 & 42.2 & 30.2 \\
\hline $15 y$ & 220 & 46.8 & 23.6 \\
\hline $16-19 y$ & 307 & 46.9 & 29.3 \\
\hline $40-49 y$ & 129 & 45.0 & 20.2 \\
\hline \multicolumn{4}{|c|}{ TaBle 11} \\
\hline \multicolumn{4}{|c|}{$1 \mathrm{~km}={ }_{---}$metres } \\
\hline Age & Sample & Percentage of correct answers & Percentage of "no attempts" \\
\hline $13 \mathrm{y}$ & 191 & 37.7 & 34.0 \\
\hline $14 \mathrm{y}$ & 225 & 50.7 & 23.1 \\
\hline $15 y$ & 220 & 56.4 & 20.5 \\
\hline $16-19 y$ & 307 & 53.7 & 27.0 \\
\hline $40-50 y$ & 129 & 69.0 & 19.4 \\
\hline
\end{tabular}

10 are still promoted as, for example, in a revision book for mathematics at Key Stage 3 ([23], p 30). Rules and procedures that bypass understanding are less likely to be remembered accurately.

Many procedures that are taught for mathematics are very unforgiving on faulty memories. Often, even one small error in the application of a procedure is enough to generate failure.

Recent research by Siegler et al. [24] found that knowledge at age 10 of division was consistently related to later mathematics proficiency. This is not happy news for the UK, if over $30 \%$ of 10 -year-old pupils do not attempt to divide 38 by 2 or 6030 by 10 .

4.4. Hypothesis 4. Problems that involve the application of multiplication and division generate more "no attempts" than those that are simply computations (see Tables 11 and 12).

The two items mix arithmetic and measurement. Over one-third of 13-year-old pupils and one-fifth of 15-yearold pupils did not attempt to divide a kilometre by 5 . The item which involves conversion of a quantity in kilometres to metres, illustrated, via the type of errors it generated, the implications of a partial recall of the rules about "moving the decimal point and adding zeros." The most frequently occurring error was 5067 metres.

4.5. Hypothesis 5. The percentage of pupils using the "no attempt" avoidance strategy is greatest for the bottom quartile of achievers.

Caveat: as questions become "harder" more of the high achievers use the "no attempt" strategy. 
TABLE 12

\begin{tabular}{lccc}
\hline Age & Sample & \multicolumn{2}{c}{$5.67 \mathrm{~km}=$ - $_{\text {metres }}$} \\
Percentage of correct answers & Percentage of "no attempts" \\
\hline $13 \mathrm{y}$ & 191 & 36.6 & 43.5 \\
$14 \mathrm{y}$ & 225 & 44.4 & 32.4 \\
$15 \mathrm{y}$ & 220 & 50.9 & 25.5 \\
$16-19 \mathrm{y}$ & 307 & 45.0 & 39.4 \\
$40-50 \mathrm{y}$ & 129 & 54.3 & 27.9 \\
\hline
\end{tabular}

TABLE 13

\begin{tabular}{lccccc}
\hline & All & BQ & TQ & BQ/All & PC \\
\hline 10 years & & & & & \\
$2) 38$ & 30.5 & 18.2 & 1.0 & 60.0 & 59.1 \\
$10) 6030$ & 31.4 & 18.2 & 1.0 & 58.0 & 44.5 \\
\hline 13 years & & & & 63.5 & 60.7 \\
$2) 38$ & 27.2 & 17.3 & 0.5 & 65.4 & 48.7 \\
$10) 6030$ & 27.2 & 17.8 & 0 & & \\
\hline 15 years & & & & 62.1 & 75.0 \\
$2) 38$ & 13.2 & 8.2 & 0 & 71.0 & 62.3 \\
$10) 6030$ & 14.1 & 10.0 & 0 & 74.0 & 55.4 \\
$4.8+5.21+6$ & 12.3 & 9.1 & 1.8 & 49.7 & 38.2 \\
$541 \times 203$ & 17.3 & 8.6 & 0.5 & 5.4 & 37.3 \\
$(2 / 5)+(3 / 8)$ & 29.1 & 13.2 & & & 45.5 \\
$9) 927$ & 33.6 & 17.7 & & & \\
\hline
\end{tabular}

All: for all students.

BQ: for the bottom quartile of total score.

TQ: for the top quartile of total score.

BQ/All: percentage of no attempts for the bottom quartile compared to all no attempts (for example, for 2) 38 for pupils of 10 years, $60.0 \%$ of the "no attempts" were from the bottom quartile of students).

PC: percentage of correct answers.

The "no attempts" for two items from the 15-minute test were analysed for the bottom quartile of scores, the top quartile, and for all scores. The main focus was on the division items 2)38 and 10)6030.

The students in the bottom quartile of achievers were contributing a high proportion of the no attempts (see Table 13). When the percentage of that contribution drops below $50 \%$ the questions generate correct scores below $40 \%$, suggesting that a larger number of the more able children are being dragged into the "no attempt" behaviour when questions become less straightforward. A related conclusion was reached by Ashcraft and Krause [17] in a study on 80 undergraduates, which investigated the correlation between math performance and math anxiety. The lower achievement of the undergraduates who were math-anxious seemed limited to more difficult math which is described as math taught at or after late elementary school.

\section{Summary}

Poor achievement levels in mathematics for a significant percentage of the population have been an issue in the UK for decades [25]. The data presented in this paper supports a number of hypotheses, which combine to suggest a final hypothesis, that is, that too many children and adults give up on mathematics learning by withdrawing from any task that is perceived as likely to result in failure, which in turn becomes a pervasive attitude. The withdrawal strategy avoids the learner being judged as wrong and thus adding to their sense of helplessness. Some of the demands of mathematics that contribute to a sense of failure, anxiety, and helplessness are based on beliefs, rather than academic necessity. These beliefs also have an effect on the way mathematics is taught with a focus on the curriculum whilst overlooking the characteristics of the learners.

The combination of "no attempts" and incorrect answers for many of the examples used above is not indicative of a successful outcome for the mathematics curriculum and how it is taught in the UK.

Finally, a 12-year-old student summed up his experiences of mathematics teaching as, "All I hear is talking, talking. It's a river." Perhaps it is time to challenge some of the mathematics beliefs that have a profound influence on the way the subject is perceived and taught and give more focus to how learners learn. 


\section{References}

[1] M. Ashcraft, E. P. Kirk, and D. Hopko, "On the cognitive consequences of mathematics anxiety," in The Development of Mathematical Skills, C. Donlan, Ed., Hove, The Psychological Corporation, 1998.

[2] R. R. Skemp, The Psychology of Learning Mathematics, Penguin, Hardmondsworth, UK, 1971.

[3] I. Lundberg and G. Sterner, "Reading, arithmetic, and task orientation-how are they related?" Annals of Dyslexia, vol. 56, no. 2, pp. 361-377, 2006.

[4] J. Hattie, Visible Learning: A Synthesis of over 800 MetaAnalyses Relating to Achievement, Routledge, Abingdon, UK, 2009.

[5] M. C. O'Connor and S. V. Paunonen, "Big Five personality predictors of post-secondary academic performance," Personality and Individual Differences, vol. 43, no. 5, pp. 971-990, 2007.

[6] C. S. Dweck, Self-Theories, Psychology Press, Philadelphia, Pa, USA, 2000.

[7] M. Seligman, Learned Optimism, Vintage Books, New York, NY, USA, 2006.

[8] S. Chinn, The Trouble with Maths: A Practical Guide to Helping Learners with Numeracy Difficulties, Routledge, Abingdon, UK, 2nd edition, 2012.

[9] D. Mtetwa and J. Garofalo, "Beliefs about mathematics: an overlooked aspect of student difficulties," Academic Therapy, vol. 24, no. 5, pp. 611-618, 1989.

[10] P. Ernest, The Psychology of Learning Mathematics, Lambert Academic Publishing, Saarbrucken, Germany, 2011.

[11] R. Porkess et al., "A world-class mathematics education for all our youngpeople," 2011, http://www.conservatives.com/ .../Vorderman\%20maths\%20report.ashx .

[12] S. Chinn, More Trouble with Maths: A Complete Guide to Identifying and Diagnosing Mathematical Learning Difficulties, Routledge, Abingdon, UK, 2012.

[13] M. V. Covington, Making the Grade: A Self-Worth Perspective on Motivation and School Reform, CUP, Cambridge, UK, 1992.

[14] S. Chinn, "Mathematics anxiety in secondary students in England," Dyslexia, vol. 15, no. 1, pp. 61-68, 2009.

[15] A. Dowker, Individual Differences in Arithmetic, Hove, Psychology Press, 2005.

[16] M. H. Ashcraft, J. A. Krause, and D. R. Hopko, "Is math anxiety a mathematical learning disability?" in Why is Math so Hard for Some Children? The Nature and Origins of Mathematical Learning Difficulties and Disabilities, M. M. M. Mazzocco and D. B. Berch, Eds., Brookes, Baltimore, Md, USA, 2007.

[17] M. H. Ashcraft and J. A. Krause, "Working memory, math performance, and math anxiety," Psychonomic Bulletin and Review, vol. 14, no. 2, pp. 243-248, 2007.

[18] R. Hembree, "The nature, effects and relief of mathematics anxiety," Journal for Research in Mathematics Education, vol. 21, pp. 33-46, 1990.

[19] S. J. Chinn, "A pilot study to compare arithmetic skill," Dyslexia Review, vol. 4, pp. 4-7, 1995.

[20] J. M. Engelhardt, "Analysis of childrens' computational errors: a qualitative approach," British Journal of Educational Psychology, vol. 47, pp. 149-154, 1977.

[21] O. D. Hadfield and K. McNeil, "The relationship between Myers-Briggs personality type and mathematics anxiety among pre-service elementary teachers," Journal of Instructional Psychology, vol. 21, no. 4, pp. 375-384, 1994.

[22] Department for Children, Schools and Families, "Getting back on track-pupils who make slow progress in Key Stage 3," Ref.
00654-2007BKT-EN, 2007, http://www.tsm-resources.com/ pdf/VordermanMathsReport.pdf.

[23] M. Chester, K. Manson, S. Little, K. Redmond et al., KS 3 Mathematics: Complete Revision and Practice, Kirkby-inFurness, Coordination Group Publications, 2004.

[24] R. S. Siegler, G. J. Duncan, P. E. Davis-Kean et al., "Early predictors of high school mathematics achievement," Pyschological Science, vol. 23, no. 7, pp. 691-697.

[25] S. Rashid and G. Brooks, "The levels of attainment in literacy and numeracy of 13- to 19-year olds in England, 1948-2009," Literacy Today, vol. 32, no. 1, pp. 13-24, 2010. 


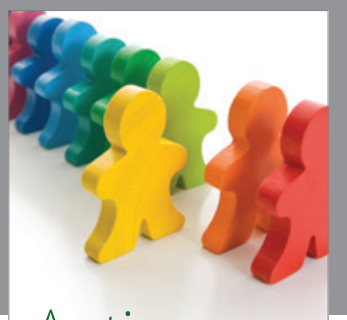

Autism

Research and Treatment
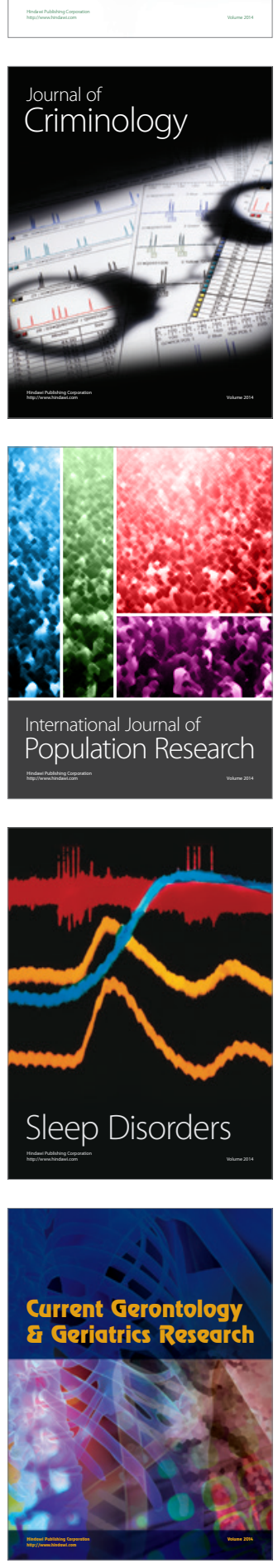
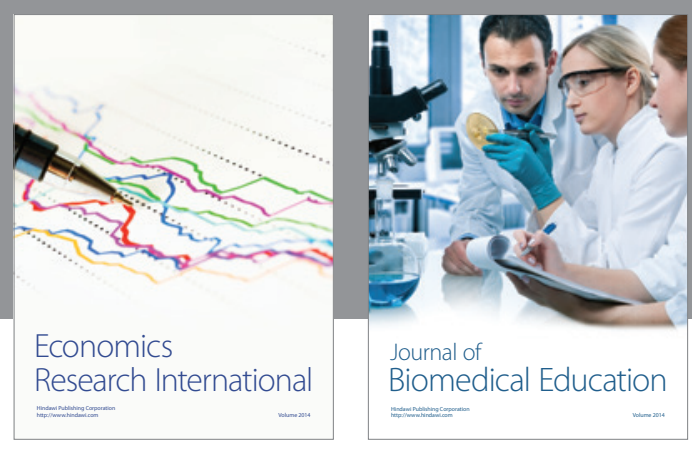

Journal of

Biomedical Education

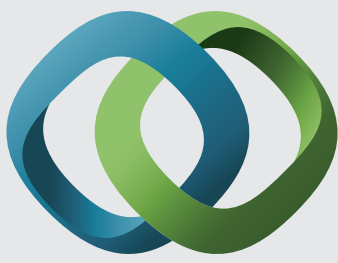

\section{Hindawi}

Submit your manuscripts at

http://www.hindawi.com
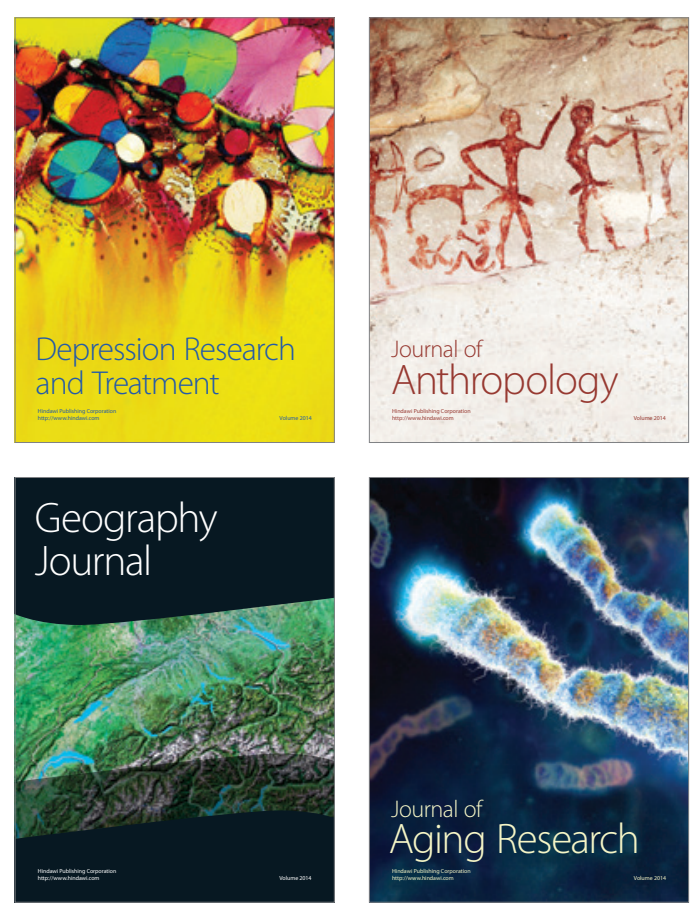

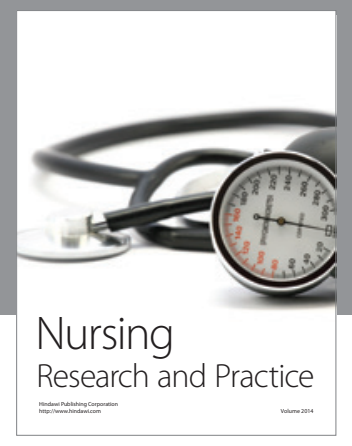

Nursing

Research and Practice

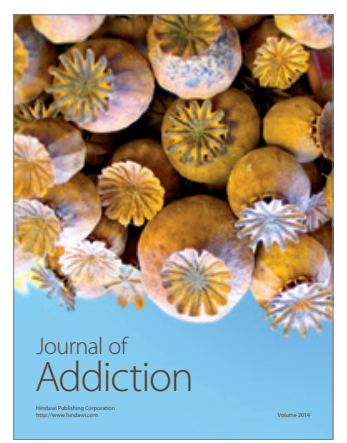

Child Development

Research

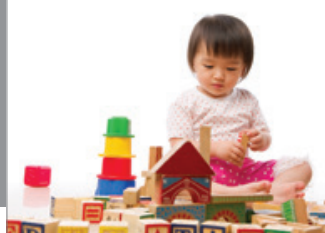

迥
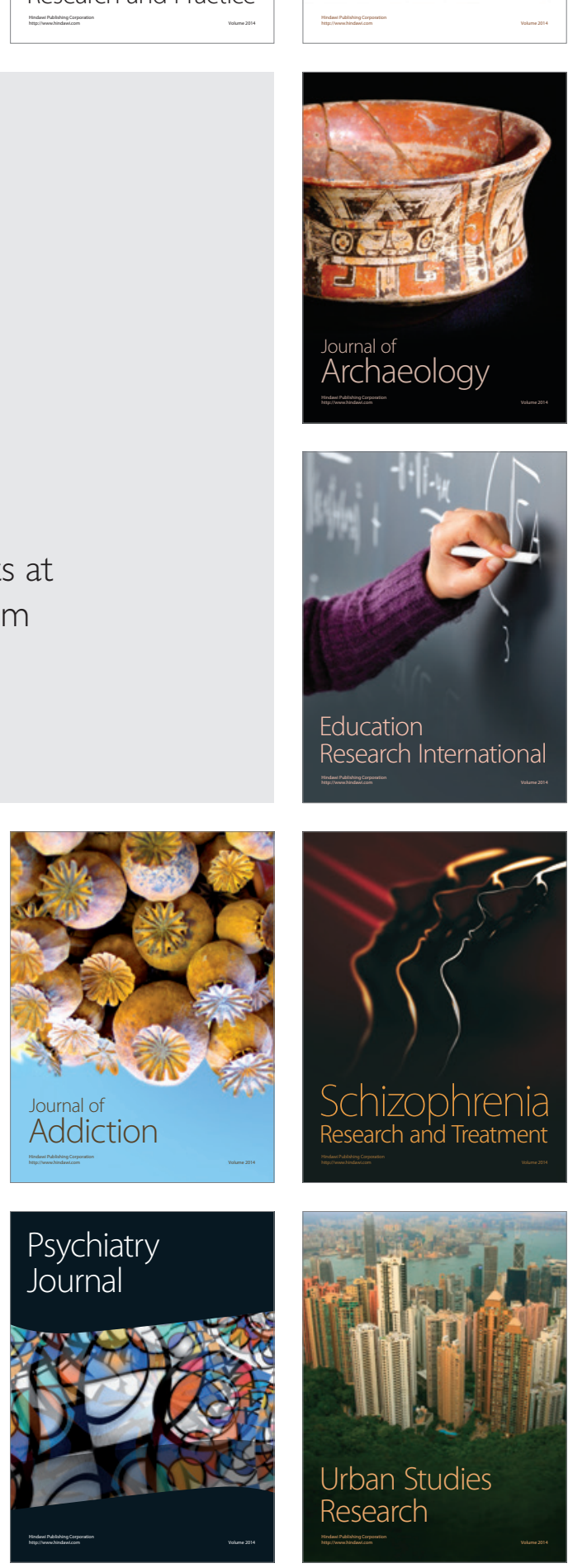